\title{
DOCK7-ANGPTL3 SNPs and their haplotypes with serum lipid levels and the risk of coronary artery disease and ischemic stroke

\author{
Wei-Jun Li ${ }^{1}$, Rui-Xing Yin ${ }^{1 *} \mathbb{D}$, Xiao-Li Cao ${ }^{2}$, Wu-Xian Chen ${ }^{1}$, Feng Huang ${ }^{1}$ and Jin-Zhen $\mathrm{Wu}^{1}$
}

\begin{abstract}
Background: Little is known about the association of the dedicator of cytokinesis 7 (DOCK7 rs1748195) and angiopoietin like 3 (ANGPTL3 rs12563308) single nucleotide polymorphisms (SNPs) and their haplotypes with serum lipid levels and the risk of coronary artery disease (CAD) and ischemic stroke (IS) in the Chinese populations. This study aimed to detect such association in a Southern Chinese Han population.
\end{abstract}

Methods: This study included 1728 subjects (CAD, 568; IS, 539; and controls, 621). Genotypes of the two SNPS were determined by the Snapshot technology.

Results: The genotypic and allelic frequencies of the rs1748195 SNP were different between CAD patients and controls $(P<0.05$ for each), the rs1748195G allele frequency was higher in CAD patients than in controls (27.6\% vs. $23.6 \%, P=0.024)$. The genotypic frequencies of the rs 12563308 SNP were also different between CAD patients and controls $(P=0.021)$. The rs 1748195 SNP was associated with an increased risk of CAD after controlling for potential confounders and Bonferroni correction $(P<0.025$ considered statistically significant; Recessive: $\mathrm{OR}=1.79,95 \% \mathrm{Cl}=1.04-3.06, P=0.017$; Log-additive: $\mathrm{OR}=1.27,95 \% \mathrm{Cl}=1.02-1.57, P=0.014)$, whereas the rs 12563308 SNP was associated with a decreased risk of CAD (Dominant: $\mathrm{OR}=0.69,95 \% \mathrm{Cl}=0.45-0.94$, $P=0.011$; Log-additive: $\mathrm{OR}=0.73,95 \% \mathrm{Cl}=0.49-0.89, P=0.009)$. The $\mathrm{rs} 1748195 \mathrm{SNP}$ was also associated with an increased risk of severity to coronary artery atherosclerosis (Dominant: $\mathrm{OR}=1.45,95 \% \mathrm{Cl}=1.07-2.11, P=0.017$; Log-additive: $\mathrm{OR}=1.35,95 \% \mathrm{Cl}=1.09-1.82, P=0.013)$. The interactions of SNP-environment on serum lipid levels and the risk of severity to coronary artery atherosclerosis, CAD and IS were noted. The rs1748195G-rs12563308T haplotype was associated with an increased angiographic severity to coronary artery atherosclerosis $(\mathrm{OR}=1.46$, $95 \% \mathrm{Cl}=1.05-2.03)$, and the risk of $\mathrm{CAD}(\mathrm{OR}=1.37,95 \% \mathrm{Cl}=1.08-1.74)$. The interactions of haplotype-hypertension on the risk of CAD and haplotype-drinking on the risk of CAD/IS were observed.

Conclusions: These results suggest that the DOCK-ANGPTL3 SNPS and their haplotypes were associated with the angiographic severity to coronary artery atherosclerosis and the risk of CAD and IS in the Southern Chinese Han population.

Keywords: Dedicator of cytokinesis 7, Angiopoietin like 3, Single nucleotide polymorphisms, Lipid, Coronary artery disease, Ischemic stroke

\footnotetext{
*Correspondence: yinruixing@163.com

'Department of Cardiology, Institute of Cardiovascular Diseases, The First

Affiliated Hospital, Guangxi Medical University, 22 Shuangyong Road,

Nanning 530021, Guangxi, People's Republic of China

Full list of author information is available at the end of the article
} 


\section{Background}

The mortality and morbidity of coronary artery disease (CAD) and ischemic stroke (IS) remain very high in different districts [1-3]. The Global Burden of Disease (GBD) 2015 study reported that the global number of deaths due to cardiovascular disease had ranged from 12.59 million in 1990 to 17.92 million in 2015. Meanwhile, the global number of deaths due to IS in 2015 was 24.93 million [4]. The prevention and treatment of the two diseases remain a great challenge to us. Though both diseases are complex multifactorial disorder, it is widely accepted that the pathological basis of the two diseases are atherosclerosis, and serum dyslipidemia plays an important role in process of coronary artery atherosclerosis [5]. The view that genetic and environmental factors such as sex, age, obesity, cigarette smoking, alcohol consumption, hypertension and hyperlipidemia contribute to suffering both the diseases was confirmed by different researches [6-12] and powerful guidelines have token the related factors into considerations when coming to prevention of the diseases $[8,9]$. Previous genome-wide association studies (GWASes) have identified many genetic variants influenced the risk of CAD or IS [13].

The dedicator of cytokinesis 7 gene (DOCK7) is located in chromosome 1p31. It encodes a guanine nucleotide exchange factor (GEF) that plays a role in axon formation and neuronal polarization. Angiopoietin like 3 gene (ANGPTL3) encodes a member of a family of secret proteins that function in angiogenesis. The encoded protein, which is expressed predominantly in the liver, is further processed into an $\mathrm{N}$-terminal coiled-coil domaincontaining chain and a C-terminal fibrinogen chain. The N-terminal chain is important for lipid metabolism, while the $\mathrm{C}$-terminal chain may be involved in angiogenesis (http://www.ncbi.nlm.nih.gov/gene/). The protein was proven to increase serum cholesterol and triglyceride (TG) levels in mice [14] and in humans [15]. ANGPTL3 lies within an intron of DOCK7, and previous GWASes showed that single nucleotide polymorphisms (SNPs) in the DOCK7-ANGPTL3 were associated with serum lipid traits, not only total cholesterol (TC) but also TG $[16,17]$. Recently, Graham et al. [18] reported that ANGPTL3 retarded the progression of atherosclerosis and reduced atherogenic lipoprotein levels in oligonucleotides targeting mice. Furthermore, using the same strategy to target human ANGPTL3, they also found that the ANGPTL3 could reduce atherogenic lipoprotein levels in humans including serum TG, LDL-C, very low density lipoprotein (VLDL) cholesterol, non-high density lipoprotein cholesterol (non-HDL-C), apolipoprotein (Apo) B, and ApoCIII levels [18]. In several previous studies, we have investigated the association of the DOCK7 rs1168013, DOCK7 rs10889332 SNPs with serum lipid levels [19], and DOCK7 rs10889353,
DOCK7 rs10889335 with serum lipid levels and the risk of CAD and IS [20]. In a recent study in a Chinese pediatric population, Shen et al. [21] have showed that the DOCK7 rs1748195 SNP was strongly associated with TG and HDL-C. However, the association of the DOCK7 rs1748195 and NGPTL3 rs12563308 SNPs with the risk of CAD and IS has not been detected previously. Therefore, the present study aimed to explore such association in a Southern Chinese Han population.

\section{Methods \\ Patients}

A total of 1107 unrelated participants were recruited from hospitalized patients in the First Affiliated Hospital, Guangxi Medical University. There were 568 CAD and 539 IS patients. CAD group included stable angina and acute coronary syndrome (unstable angina, non-ST segment elevation myocardial infarction and ST segment elevation myocardial infarction). The diagnosis of CAD based on typical angina or discomfort, electrocardigraphic changes (ST-segment depression or elevation of $\geq 0.5 \mathrm{~mm}$, T-wave inversion of $\geq 3 \mathrm{~mm}$ in $\geq 3$ leads, or left bundle branch block), increases in the cardiac makers (creatinine kinase-MB and troponin $\mathrm{T}$ or I), as well as positive coronary angiograms (coronary stenosis $\geq 50 \%$ in at least one of the three main coronary arteries or their major branches which reviewed by two independent angiographers who were both blinded to the clinical and genotype results) [22]. The angiographic severity of coronary artery atherosclerosis was classified according to the number of coronary vessels with significant stenosis (luminal narrowing $\geq 50 \%$ ) as one-, two-, or three-vessel disease in the three major coronary arteries. Some CAD patients had taken medicines before they were admitted to hospital. A total of 171 (30.11\%) patients used one or more than one lipid-lowing drugs such as fibrates or statins. All of the IS patients received a strict neurological examination and brain magnetic resonance imaging (MRI). The diagnosis and classification of IS was according to the Trial of Org 10,712 in Acute Stroke Treatment (TOAST) criteria, and patients included met one or two criteria: largeartery thrombosis and small-vessel occlusion [23]. There were 149 patients (27.64\%) using lipid-lowing drugs. The participants with a history of autoimmune, hematologic, neoplastic, liver, renal, thyroid, and type 1 diabetes were rejected. CAD subjects with a history of IS or IS participants with a history of CAD were not included in this study. There were 58 patients not included in this study because of the co-existence of both CAD and IS.

\section{Controls}

A total of 621 control subjects matched by age, gender, ethnic group (Han nationality in Guangxi, China) 
were included. All of the individuals were randomly selected from the Physical Examination Center of the First Affiliated Hospital during the same period. Questionnaires, history-taking, strict clinical examination and image examinations (computed tomography or MRI) were used to insure all the participants free of CAD and IS. They did not take drugs known to affect serum lipid levels (such as statins or fibrates, betablockers, diuretics, or hormones). All participants have provided their written informed consents and the study protocol was approved by the Ethics Committee of the First Affiliated Hospital, Guangxi Medical University (No. Lunshen 2009-Guike-018; Jan. 7, 2009). The reported investigations were in accordance with the principles of the Declaration of Helsinki.

\section{Biochemical measurements}

A venous blood sample of $5 \mathrm{ml}$ was obtained from all participants after at least $12 \mathrm{~h}$ of fasting. A part of the sample $(2 \mathrm{ml})$ was collected into glass tubes and used to measure serum lipid levels, another part $(3 \mathrm{ml})$ was stored in the tubes contained anticoagulants $(4.80 \mathrm{~g} / \mathrm{L}$ citric acid, $14.70 \mathrm{~g} / \mathrm{L}$ glucose, and $13.20 \mathrm{~g} / \mathrm{L}$ tri-sodium citrate) and used to extract deoxyribonucleic acid (DNA). The interval between the disease attack and blood collection for analysis was within $36 \mathrm{~h}$. The levels of serum TC, TG, HDL-C, and LDL-C were determined by enzymatic methods with commercially available kits (RANDOX Laboratories). Serum ApoA1 and ApoB levels were detected by the immunoturbidimetric immunoassay. The normal values in our Clinical Science Experiment Center were $3.10-5.17 \mathrm{mmol} / \mathrm{L}$ for TC, 0.56-1.70 mmol/L for TG, 0.91-1.81 mmol/L for HDL-C, 2.70-3.20 mmol/L for LDL-C, 1.00-1.78 g/L for ApoA1, 0.63-1.14 g/L for ApoB, and 1.00-2.50 for the ApoA1/ ApoB ratio. The participants with $\mathrm{TC}>5.17 \mathrm{mmol} / \mathrm{L}$, and/ or TG $>1.70 \mathrm{mmol} / \mathrm{L}$ were defined as hyperlipidemic $[24,25]$. Hypertension was defined as a systolic blood pressure of $140 \mathrm{mmHg}$ or greater, and/or a diastolic blood pressure of $90 \mathrm{mmHg}$ or higher [26]. Drinking based on alcohol consumption (yes or no). Individuals' age was divided into $>60$-year or $\leq 60$-year subgroups. Body mass index (BMI) was calculated according to the values of weight divided by height squared $\left(\mathrm{kg} / \mathrm{m}^{2}\right)$. A BMI of $\leq 24,24-28$, and $>28 \mathrm{~kg} / \mathrm{m}^{2}$ was defined as normal weight, overweight and obesity; respectively. Smoking was defined as current smoking (yes or no).

\section{SNP selection}

The selection of SNPs was according to the following assumption: (1) Selected SNPs were Tagging SNPs established by Haploview (Broad Institute or MIT and Harvard, Cambridge, MA, USA, version 4.2); (2) SNP information was obtained from NCBI dbSNP Build 132 (http://www.ncbi.nlm. nih.gov/SNP/); (3) SNPs were restricted to the minor allele frequency $(\mathrm{MAF})>1 \%$; and (4) SNPs in the gene might be associated with the serum lipid levels or cardiovascular disease in previous studies [14-21].

\section{Genotyping}

Genomic DNA was extracted from leucocytes of venous blood using the phenol-chloroform method. Genotyping of the SNPs was accomplished by the Snapshot technology platform in the Center for Human Genetics Research, Shanghai Genesky Bio-Tech Co. Ltd. [25, 27-29]. The restriction enzymes for the loci were SAP (Promega) and Exonucleasel (Epicentre). The sense and antisense primers were 5'-AGAGGAGGAGCTCCATTCTTATA 'TTTTTG-3' and 5'-AACACTGCAAGTCTGTCTCACA TAGGA-3' for the rs1748195 SNP; and 5'-GGAG AATTTTGGTTGGGCCTAGA-3' and 5'-TGCTTTGT GATCCCAAGTAGAAAACA-3' for the rs12563308 SNP; respectively.

\section{Statistical analyses}

The statistical software of SPSS22.0 (SPSS Inc., Chicago, IL, USA) was used to carry out the statistical analyses. Quantiative variables were expressed as mean \pm standard deviation (serum TG levels were expressed as medians and interquartile ranges). Qualitative variables were expressed as percentage. Allele frequency was determined via direct counting, and the standard goodnessof-fit test was used to test the Handy-Weinberg equilibrium (HWE). A chi-square analysis was used to evaluate the genotype distribution. The student's unpaired $t$-test was used to test the general characteristics between patient and control groups. Analysis of covariance (ANCOVA) was used to test the association of genotypes and serum lipid parameters. The interactions of SNP- or haplotype-environment on serum lipid levels were detected by factorial regression analysis after controlling for potential confounders. Bonferroni correction was employed for variants associated with serum lipid levels, and a $P$-value $<0.025$ was considered statistical significant (corresponding to $P<0.05$ after adjusting for two independent tests). Meanwhile, the $P$-value of interaction $\left(P_{\mathrm{I}}\right) \leq 0.005$ was considered statistically significant after Bonferroni correction. The association of genotypes and angiographic severity to atherosclerosis was detected by the unconditional logistic regression after adjusting related environmental factors, and the gene-environment interactions on the angiographic severity to atherosclerosis were tested by polytomous logistic regression for ordinal response. The association of genotypes and the risk of CAD and IS, also the SNP- or haplotype-environment interactions on the risk of CAD and IS were tested by the 
unconditional logistic regression after gender, age, BMI, smoking, alcohol consumption, hypertension and hyperlipidemia were adjusted $[8,9,20,25]$. The correlation risk was estimated by odds ratio (OR) and 95\% confidence interval $(95 \% \mathrm{CI})$ and $P<0.025$ considered statistical significant after Bonferroni correction. The pattern of pairwise linkage disequiblirium (LD) between the two SNPs was measured by $D^{\prime}$ and $r^{2}$ using the SHEsis software [30]. A two-tailed $P$-value less than 0.05 was considered statistically significant for the remaining variables. Haplotype frequency was determined by means of the algorithms implemented in the PHASE program.

\section{Results}

\section{General characteristics of the participants}

As shown in Table 1, the mean values of BMI, systolic blood pressure, pulse pressure, and ApoB levels were higher but diastolic blood pressure, alcohol consumption, TC, HDL-C and LDL-C levels were lower in CAD patients than in controls $(P<0.05$ for all). The values of BMI, systolic blood pressure, diastolic blood pressure, pulse pressure levels were higher but alcohol consumption, TC, HDL-C and LDL-C levels were lower in IS patients than in controls.

\section{Genotypic and allelic frequencies of the subjects}

The genotypic and allelic frequencies of the DOCK7ANGPTL3 polymorphisms are summarized in Table 2. The genotype distribution of the two SNPs was consistent with the Hardy-Weinberg equilibrium in CAD/IS patients and controls $(P>0.05$ for all). For the DOCK7 rs1748195 SNP, the genotypic and allelic frequencies were different between CAD patients and controls $(P<0.05$ for each), the frequency of the rs1748195G allele was higher in CAD patients than in controls (27.6\% vs. $23.6 \%, P=0.024)$. For the ANGPTL3 rs12563308 SNP, the genotypic frequencies were also different between CAD patients and controls $(P=0.021)$. But no significant difference in the genotypic and allelic frequencies of the two SNPs was observed between IS patients and controls.

\section{Genotypes and serum lipid levels}

As shown in Table 3, we found that the DOCK7 rs1748195 and ANGPTL3 rs12563308 SNPs were not associated with serum lipid traits in the controls $(P>0.025$ for all).

\section{DOCK7-ANGPTL3 SNPs and the risk of CAD and IS}

The associations of DOCK7-ANGPTL3 SNPs and the risk of CAD and IS are shown in Table 4. The SNPs of rs1748195 and rs12563308 were associated with the risk of CAD after controlling for potential confounders including gender, age, BMI, cigarette smoking, alcohol consumption, hypertension and hyperlipidemia (a $P<0.025$ was considered statistically significant after Bonferroni correction). The rs1748195 SNP was associated with an increased risk of CAD (Recessive: OR $=1.79,95 \%$ $\mathrm{CI}=1.04-3.06, P=0.017 ;$ Log-additive: $\mathrm{OR}=1.27,95 \%$ $\mathrm{CI}=1.02-1.57, \quad P=0.014), \quad$ whereas the $\mathrm{rs} 12563308$ SNP was associated with a decreased risk of CAD

Table 1 General characteristic of the participants

\begin{tabular}{|c|c|c|c|c|c|}
\hline Characteristic & Control $(n=621)$ & CAD $(n=568)$ & IS $(n=539)$ & $P_{\text {CAD }}$ & $P_{I S}$ \\
\hline Male/Female & $449 / 172$ & $418 / 150$ & $389 / 150$ & 0.617 & 0.960 \\
\hline Age, year & $61.67 \pm 11.99$ & $62.26 \pm 10.55$ & $62.81 \pm 12.37$ & 0.739 & 0.868 \\
\hline BMI $\left(\mathrm{kg} / \mathrm{m}^{2}\right)$ & $22.65 \pm 3.20$ & $23.91 \pm 3.26$ & $23.39 \pm 3.54$ & 0.006 & 0.009 \\
\hline Systolic blood pressure, $\mathrm{mmHg}$ & $128.26 \pm 19.00$ & $133.16 \pm 23.49$ & $147.52 \pm 22.00$ & 0.000 & 0.004 \\
\hline Diastolic blood pressure, $\mathrm{mmHg}$ & $80.56 \pm 11.41$ & $79.19 \pm 14.27$ & $83.71 \pm 12.93$ & 0.022 & 0.003 \\
\hline Pulse pressure, $\mathrm{mmHg}$ & $47.70 \pm 13.74$ & $53.98 \pm 17.68$ & $63.81 \pm 17.76$ & 0.000 & 0.000 \\
\hline Cigarette smoking, n (\%) & $244(39.2)$ & $244(43.0)$ & $221(41.6)$ & 0.199 & 0.553 \\
\hline Alcohol consumption, n (\%) & $270(43.4)$ & $130(22.9)$ & $150(28.2)$ & 0.000 & 0.000 \\
\hline Total cholesterol, mmol/L & $4.88 \pm 1.06$ & $4.54 \pm 1.20$ & $4.52 \pm 1.15$ & 0.007 & 0.031 \\
\hline Triglyceride, mmol/L & $1.37(1.78)$ & $1.67(1.12)$ & $1.62(1.38)$ & 0.748 & 0.465 \\
\hline $\mathrm{HDL}-\mathrm{C}(\mathrm{mmol} / \mathrm{L})$ & $1.90 \pm 0.48$ & $1.14 \pm 0.34$ & $1.23 \pm 0.40$ & 0.000 & 0.000 \\
\hline LDL-C (mmol/L) & $2.73 \pm 0.78$ & $2.71 \pm 1.00$ & $2.68 \pm 0.90$ & 0.000 & 0.000 \\
\hline Apolipoprotein (Apo) A1, g/L & $1.41 \pm 0.27$ & $1.02 \pm 0.32$ & $1.02 \pm 0.23$ & 0.895 & 0.051 \\
\hline ApoB, g/L & $0.90 \pm 0.21$ & $0.91 \pm 0.27$ & $0.89 \pm 0.24$ & 0.000 & 0.080 \\
\hline ApoA1/ApoB & $1.64 \pm 0.51$ & $1.30 \pm 1.83$ & $1.27 \pm 0.60$ & 0.210 & 0.745 \\
\hline
\end{tabular}

CAD coronary artery disease, IS ischemic stroke, $H D L-C$ high-density lipoprotein cholesterol, $L D L$ - $C$ low-density lipoprotein cholesterol, $P_{C A D}$, the $P$ value between CAD patients and controls; $P_{\mathrm{IS}}$, the $P$ value between IS patients and controls. The value of triglyceride was median (interquartile range), the difference between CAD/IS patients and controls was determined by the Wilcoxon-Mann-Whitney test 
Table 2 Genotypic and allelic frequencies of the DOCK7-ANGPTL3 SNPs in controls and cases

\begin{tabular}{|c|c|c|c|c|c|}
\hline SNP/Genotype/Allele & Control (\%) & CAD (\%) & IS (\%) & $P_{C A D}$ & $P_{\text {IS }}$ \\
\hline \multicolumn{6}{|l|}{ Rs1748195 } \\
\hline $\mathrm{CC}$ & $361(58.1)$ & $303(53.3)$ & $311(57.7)$ & & \\
\hline CG & 227 (36.6) & $216(38.0)$ & $188(34.9)$ & & \\
\hline GG & $33(5.3)$ & $49(8.7)$ & $40(7.4)$ & 0.047 & 0.321 \\
\hline C & 949 (76.4) & $822(72.4)$ & $810(75.1)$ & & \\
\hline G & $293(23.6)$ & $314(27.6)$ & $268(24.9)$ & 0.024 & 0.476 \\
\hline$P_{\mathrm{HWE}}$ & 0.728 & 0.240 & 0.123 & & \\
\hline $\mathrm{CC} / \mathrm{CG}$ & $588(94.7)$ & $519(91.3)$ & $499(92.6)$ & & \\
\hline GG & $33(5.3)$ & $49(8.7)$ & $40(7.4)$ & 0.024 & 0.140 \\
\hline \multicolumn{6}{|l|}{ Rs12563308 } \\
\hline$\pi$ & $534(86.0)$ & $517(91.0)$ & $479(88.8)$ & & \\
\hline $\mathrm{CT}$ & $84(13.5)$ & $48(8.5)$ & $57(10.6)$ & & \\
\hline $\mathrm{CC}$ & $3(0.5)$ & $3(0.5)$ & $3(0.6)$ & 0.021 & 0.305 \\
\hline T & $1152(92.8)$ & $1082(95.2)$ & $1015(94.2)$ & & \\
\hline$C$ & $80(7.2)$ & $54(4.8)$ & $63(5.8)$ & 0.067 & 0.518 \\
\hline$P_{\text {HWE }}$ & 0.876 & 0.112 & 0.364 & & \\
\hline$\pi$ & $534(86.0)$ & $517(91.0)$ & 479 (88.8) & & \\
\hline $\mathrm{CT} / \mathrm{CC}$ & $87(14.0)$ & $51(9.0)$ & $60(11.2)$ & 0.007 & 0.142 \\
\hline
\end{tabular}

SNP single nucleotide polymorphisms, CAD coronary artery disease, IS ischemic disease, HWE Hardy- Weinberg equilibrium, $P_{\mathrm{HWE}}$ the $P$ value of the Hardy-Weinberg equilibrium, $P_{\text {CAD }}$ the $P$ value between CAD patients and controls, $P_{\text {IS }}$ the $P$ value between IS patients and controls

Table 3 Association of the DOCK7-ANGPTL3 SNPs and serum lipid levels in controls

\begin{tabular}{|c|c|c|c|c|c|c|c|c|}
\hline Genotype & $\mathrm{n}$ & $\mathrm{TC}(\mathrm{mmol} / \mathrm{L})$ & TG (mmol/L) & $\mathrm{HDL}-\mathrm{C}(\mathrm{mmol} / \mathrm{L})$ & LDL-C (mmol/L) & ApoA1 (g/L) & ApoB (g/L) & ApoA1/ApoB \\
\hline \multicolumn{9}{|l|}{ Rs1748195 } \\
\hline $\mathrm{CC}$ & 361 & $4.92 \pm 1.11$ & $1.37(0.90)$ & $1.91 \pm 0.47$ & $2.70 \pm 0.77$ & $1.42 \pm 0.28$ & $0.89 \pm 0.20$ & $1.66 \pm 0.53$ \\
\hline CG & 227 & $4.83 \pm 1.00$ & $1.18(0.70)$ & $1.88 \pm 0.49$ & $2.74 \pm 0.80$ & $1.40 \pm 0.27$ & $0.91 \pm 0.22$ & $1.62 \pm 0.51$ \\
\hline GG & 33 & $4.98 \pm 0.74$ & $1.25(0.69)$ & $1.93 \pm 0.55$ & $2.85 \pm 0.68$ & $1.40 \pm 0.20$ & $0.94 \pm 0.21$ & $1.56 \pm 0.40$ \\
\hline$F$ & - & 0.661 & 2.381 & 0.327 & 0.685 & 0.434 & 0.959 & 0.893 \\
\hline P & - & 0.517 & 0.063 & 0.721 & 0.504 & 0.648 & 0.384 & 0.410 \\
\hline$C C+C G$ & 588 & $4.88 \pm 1.07$ & $1.32(0.84)$ & $1.90 \pm 0.48$ & $2.72 \pm 0.78$ & $1.41 \pm 0.28$ & $0.90 \pm 0.21$ & $1.65 \pm 0.52$ \\
\hline GG & 33 & $4.98 \pm 0.74$ & 1.19 (0.69) & $1.94 \pm 0.55$ & $2.85 \pm 0.68$ & $1.40 \pm 0.20$ & $0.94 \pm 0.21$ & $1.56 \pm 0.40$ \\
\hline$F$ & - & 0.283 & 0.171 & 0.172 & 0.994 & 0.108 & 0.933 & 0.931 \\
\hline$P$ & - & 0.595 & 0.679 & 0.678 & 0.318 & 0.742 & 0.334 & 0.335 \\
\hline \multicolumn{9}{|l|}{ Rs12563308 } \\
\hline$\pi$ & 534 & $4.90 \pm 1.08$ & $1.42(0.89)$ & $1.91 \pm 0.49$ & $2.73 \pm 0.79$ & $1.42 \pm 0.28$ & $0.90 \pm 0.21$ & $1.64 \pm 0.48$ \\
\hline $\mathrm{CT}$ & 84 & $4.80 \pm 0.87$ & $1.21(0.87)$ & $1.86 \pm 0.46$ & $2.68 \pm 0.72$ & $1.38 \pm 0.21$ & $0.89 \pm 0.20$ & $1.66 \pm 0.70$ \\
\hline CC & 3 & $5.41 \pm 0.83$ & 1.17 (0.47) & $1.99 \pm 0.50$ & $3.11 \pm 1.05$ & $1.43 \pm 0.11$ & $1.08 \pm 0.26$ & $1.39 \pm 0.43$ \\
\hline$F$ & - & 0.842 & 0.466 & 0.450 & 0.553 & 0.826 & 1.260 & 0.409 \\
\hline P & - & 0.431 & 0.627 & 0.638 & 0.575 & 0.438 & 0.284 & 0.665 \\
\hline$\pi$ & 534 & $4.90 \pm 1.09$ & $1.42(0.89)$ & $1.91 \pm 0.49$ & $2.73 \pm 0.79$ & $1.42 \pm 0.28$ & $0.90 \pm 0.21$ & $1.64 \pm 0.48$ \\
\hline$C T+C C$ & 87 & $4.80 \pm 0.87$ & $1.20(0.86)$ & $1.86 \pm 0.46$ & $2.69 \pm 0.71$ & $1.38 \pm 0.20$ & $0.89 \pm 0.21$ & $1.65 \pm 0.69$ \\
\hline$F$ & - & 0.672 & 0.993 & 0.671 & 0.195 & 1.566 & 0.108 & 0.014 \\
\hline P & - & 0.413 & 0.334 & 0.413 & 0.659 & 0.211 & 0.742 & 0.906 \\
\hline
\end{tabular}

TC total cholesterol, TG triglyceride, $H D L-C$ high-density lipoprotein cholesterol, $L D L-C$ low-density lipoprotein cholesterol, $A p o A 1$ apolipoprotein $\mathrm{A} 1, A p o B$ apolipoprotein $\mathrm{B}$. The value of triglyceride was presented as median (interquartile range), and the difference among the different genetic models was determined by Kruskal-Wallis test. A $P<0.025$ was considered statistically significant after Bonferroni correction 
Table 4 Genotypes of the two DOCK7-ANGPTL3 SNPs and the risk of CAD and IS

\begin{tabular}{|c|c|c|c|c|c|c|}
\hline SNP/Model & Ref. Genotype & Effect Genotype & $(\mathrm{OR} 95 \% \mathrm{CI})_{\mathrm{CAD}}$ & $P_{C A D}$ & IS (OR 95\% CI) IS & $P_{\text {IS }}$ \\
\hline \multicolumn{7}{|l|}{ rs1748195 } \\
\hline \multirow[t]{2}{*}{ Codominant } & \multirow[t]{2}{*}{ CC } & $C G$ & $1.16(0.88-1.54)$ & \multirow[t]{2}{*}{0.058} & $0.93(0.69-1.6)$ & \multirow[t]{2}{*}{0.221} \\
\hline & & GG & $1.90(1.10-3.29)$ & & 1.59 (0.89-2.84) & \\
\hline Dominant & $\mathrm{CC}$ & CG/GG & $1.25(0.96-1.64)$ & 0.098 & $1.01(0.76-1.35)$ & 0.933 \\
\hline Recessive & $\mathrm{CC} / \mathrm{CG}$ & GG & $1.79(1.04-3.06)$ & 0.017 & $1.63(0.92-2.88)$ & 0.092 \\
\hline Overdomiant & $\mathrm{CC} / \mathrm{GG}$ & $C G$ & $1.09(0.83-1.43)$ & 0.552 & $0.89(0.66-1.19)$ & 0.439 \\
\hline Log-additve & - & - & $1.27(1.02-1.57)$ & 0.014 & $1.09(0.87-1.37)$ & 0.450 \\
\hline \multicolumn{7}{|l|}{ Rs12563308 } \\
\hline \multirow[t]{2}{*}{ Codominant } & \multirow[t]{2}{*}{$\pi$} & CT & $0.67(0.44-1.03)$ & \multirow[t]{2}{*}{0.192} & $0.75(0.48-1.16)$ & \multirow[t]{2}{*}{0.408} \\
\hline & & $\mathrm{CC}$ & $1.17(0.17-7.99)$ & & $1.28(0.15-11.62)$ & \\
\hline Dominant & $\pi$ & $\mathrm{CT} / \mathrm{CC}$ & $0.69(0.45-0.94)$ & 0.011 & $0.76(0.49-1.17)$ & 0.206 \\
\hline Recessive & TT/CT & CC & $1.23(0.18-8.44)$ & 0.834 & $1.33(0.15-11.62)$ & 0.799 \\
\hline Overdomiant & TT/CC & $\mathrm{CT}$ & $0.67(0.44-1.03)$ & 0.068 & $0.75(0.48-1.16)$ & 0.187 \\
\hline Log-additve & - & - & $0.73(0.49-0.89)$ & 0.009 & $0.79(0.53-1.19)$ & 0.264 \\
\hline
\end{tabular}

SNP single nucleotide polymorphisms, CAD coronary artery disease, IS ischemic disease, OR (95\%Cl) Odds ratio (OR) and $95 \%$ confidence interval (CI) between patients and controls

(Dominant: $\mathrm{OR}=0.69,95 \% \mathrm{CI}=0.45-0.94, P=0.011$; Log-additive: $\mathrm{OR}=0.73,95 \% \mathrm{CI}=0.49-0.89, P=0.009)$. However, no significant association was found between the two SNPs and IS.

\section{DOCK7-ANGPTL3 SNPs and the angiographic severity of CAD}

As shown in Table 5, the rs1748195 SNP was associated with an increased risk of severity to coronary artery atherosclerosis measured by coronary angiography in CAD patients in different genetic models (Dominant: $\mathrm{OR}=1.45,95 \% \mathrm{CI}=1.07-2.11, P=0.017$; Log-additive: $\mathrm{OR}=1.35,95 \% \mathrm{CI}=1.09-1.82, P=0.013)$. There was no association of the rs12563308 SNP and the risk of severity to coronary artery atherosclerosis in our research.

\section{SNP-environment interactions on serum lipid levels and coronary atherosclerosis}

The interactions of the DOCK7-ANGPTL3 SNPs and sex, age, BMI, smoking, and drinking on serum lipid levels and the severity to atherosclerosis in CAD patients are shown in Table 6 and Fig. 1. The rs12563308 SNP interacted with alcohol consumption to decrease serum TC levels (Fig. 1a), and interacted with $B M I \geq 24 \mathrm{~kg} / \mathrm{m}^{2}$ to increase the ApoA1/ApoB ratio (Fig. 1b). The rs1748195 SNP interacted with alcohol consumption to decrease serum ApoB levels (Fig. 1c). We also found that the rs1748195 SNP interacted with BMI to influence the severity to atherosclerosis in CAD patients. In CAD patients with $\mathrm{BMI} \leq 24 \mathrm{~kg} / \mathrm{m}^{2}$, the rs1748195G allele carriers had higher risk of severity to coronary artery

Table 5 Effect of the DOCK7-ANGPTL3 SNPs on angiographic severity of CAD

\begin{tabular}{|c|c|c|c|c|c|c|}
\hline \multirow[t]{2}{*}{ SNP/Genotype } & \multicolumn{3}{|c|}{ Rs1748195 } & \multicolumn{3}{|c|}{ Rs12563308 } \\
\hline & & OR $(95 \% \mathrm{Cl})$ & $P$ & & OR $(95 \% \mathrm{Cl})$ & $P$ \\
\hline \multirow[t]{3}{*}{ Codominant } & CC & 1 & & $\pi$ & 1 & \\
\hline & CG & $1.40(0.94-2.08)$ & 0.142 & $\mathrm{TC}$ & $0.89(0.46-1.70)$ & 0.859 \\
\hline & GG & $1.71(0.81-3.61)$ & & CC & $0.57(0.05-6.73)$ & \\
\hline \multirow[t]{2}{*}{ Dominant } & $\mathrm{CC}$ & 1 & & $\pi$ & 1 & \\
\hline & $\mathrm{CG} / \mathrm{GG}$ & $1.45(1.07-2.11)$ & 0.017 & $\mathrm{CT} / \mathrm{CC}$ & $0.86(0.46-1.63)$ & 0.660 \\
\hline \multirow[t]{2}{*}{ Recessive } & $\mathrm{CC} / \mathrm{CG}$ & 1 & & $\mathrm{TT} / \mathrm{CT}$ & 1 & \\
\hline & GG & $1.49(0.72-3.10)$ & 0.271 & $\mathrm{CC}$ & $0.58(0.05-6.80)$ & 0.671 \\
\hline \multirow[t]{2}{*}{ Log-additve } & C & 1 & & $\mathrm{~T}$ & 1 & \\
\hline & G & $1.35(1.09-1.82)$ & 0.013 & C & $0.86(0.48-1.54)$ & 0.614 \\
\hline
\end{tabular}

Based to different number of main vessel stenosis by coronary angiography in CAD patients, Polytomous Logistic Regression for Ordinal Response was employeed to assess the severity, and environmental factors like sex, age, BMI, cigarette smoking, alcohol consumption, hypertension, hyperlipidemia were adjusted. A $P<0.025$ was considered statistically significant after Bonferroni correction 
Table 6 The $P_{1}$ values for interactions of genotypes and drinking, smoking, and BMI on serum lipid levels and angiographic severity of coronary atherosclerosis in CAD

\begin{tabular}{|c|c|c|c|c|c|c|c|c|}
\hline \multirow[t]{2}{*}{ SNP/Factor } & \multicolumn{7}{|l|}{ Lipid } & \multirow[t]{2}{*}{$P_{\text {CAS }}$} \\
\hline & $\mathrm{TC}$ & TG & $\mathrm{HDL}-\mathrm{C}$ & LDL-C & ApoA1 & ApoB & ApoA1/B & \\
\hline \multicolumn{9}{|l|}{ Rs1748195 } \\
\hline Sex & 0.987 & 0.417 & 0.561 & 0.942 & 0.403 & 0.632 & 0.948 & 0.18 \\
\hline Age & 0.591 & 0.790 & 0.435 & 0.145 & 0.842 & 0.621 & 0.957 & 0.40 \\
\hline BMI & 0.810 & 0.705 & 0.728 & 0.878 & 0.446 & 0.493 & 0.481 & 0.02 \\
\hline Smoking & 0.552 & 0.876 & 0.840 & 0.194 & 0.209 & 0.816 & 0.949 & 0.50 \\
\hline Drinking & 0.374 & 0.609 & 0.903 & 0.483 & 0.564 & 0.002 & 0.142 & 0.98 \\
\hline \multicolumn{9}{|l|}{ Rs12563308 } \\
\hline Sex & 0.457 & 0.603 & 0.840 & 0.849 & 0.707 & 0.998 & 0.867 & 0.85 \\
\hline Age & 0.800 & 0.982 & 0.140 & 0.247 & 0.104 & 0.365 & 0.210 & 0.56 \\
\hline BMI & 0.380 & 0.517 & 0.209 & 0.236 & 0.307 & 0.082 & 0.001 & 0.17 \\
\hline Smoking & 0.596 & 0.941 & 0.497 & 0.384 & 0.473 & 0.618 & 0.527 & 0.45 \\
\hline Drinking & 0.002 & 0.562 & 0.180 & 0.267 & 0.099 & 0.228 & 0.208 & 0.31 \\
\hline
\end{tabular}

SNP single nucleotide polymorphism, TC total cholesterol, TG triglyceride, $H D L-C$ high-density lipoprotein cholesterol, $L D L-C$ low-density lipoprotein cholesterol, $A p o A 1$ apolipoprotein $A 1, A p o B$ apolipoprotein $\mathrm{B}, C A D$ coronary artery disease, $I S$ ischemic stroke, $B M I$ body mass index. The $P_{1}$ values for interactions were detected by ANCOA, and a $P \leq 0.005$ was considered statistically significant after Bonferroni correction; $P_{\text {CAS, }}$ the $P$ interaction value of angiographic severity to coronary atherosclerosis in CAD patients, and the Polytomous Logistic Regression for Ordinal Response was employeed. A $P_{\text {CAS }} \leq 0.025$ was considered statistically significant after the rest four environmental factors was adjusted when one of the environmental factors interactions was detected

atherosclerosis than the rs1748195G allele non-carriers $\left(P_{\mathrm{CAS}}=0.02, \mathrm{OR}=1.83,95 \% \mathrm{CI}=1.07-3.12\right)$.

\section{SNP-environment interactions on the risk of CAD and IS}

As shown in Table 7 and Fig. 2, the rs12563308TT-sex (male) interaction increased the risk of CAD and IS (Fig. 2a; $P_{\mathrm{CAD}}=0.016, \quad \mathrm{OR}=2.82,95 \% \mathrm{CI}=2.02-4.00$; $\left.P_{\mathrm{IS}}=0.07, \quad \mathrm{OR}=2.52, \quad 95 \% \quad \mathrm{CI}=1.74-3.66\right)$. But the rs $12563308 \mathrm{CT} / \mathrm{CC}$-drinking (yes) interaction decreased the risk of CAD and IS (Fig. 2a; $P_{\mathrm{CAD}}=0.010, \mathrm{OR}=0.57$, $95 \% \mathrm{CI}=0.32-0.82 ; P_{\mathrm{IS}}=0.013, \mathrm{OR}=0.68,95 \% \mathrm{CI}=0.35-$ 0.87 ). The rs12563308TT-hypertension (yes) interaction increased the risk of CAD (Fig. $2 \mathrm{a} ; P_{\mathrm{CAD}}=0.019, \mathrm{OR}=$ $2.80,95 \% \mathrm{CI}=2.08-3.78)$ but not IS $\left(P_{\mathrm{IS}}=0.582\right)$. The
rs1748195CC/CG-hypertension (yes) interaction increased the risk of $\mathrm{CAD}$ (Fig. 2b; $P_{\mathrm{CAD}}=0.005, \mathrm{OR}=2.58$, $95 \% \mathrm{CI}=1.63-3.45)$ but not IS $\left(P_{\mathrm{IS}}=0.458\right)$.

\section{LD analyses, haplotypes and the risk of atherosclerosis and CAD/IS}

As shown in Table 8, strong LD was found between the two SNPs in CAD and IS patients $\left(D^{\prime}=0.88-0.91\right)$. Haplotype analyses showed that the haplotype of rs1748195G-rs12563308T was associated with an increased angiographic severity to atherosclerosis (OR = $1.46,95 \% \mathrm{CI}=1.05-2.03)$. The haplotype of rs1748195Grs12563308T was also associated with an increased risk of $\mathrm{CAD}(\mathrm{OR}=1.37,95 \% \mathrm{CI}=1.08-1.74)$ but not IS.

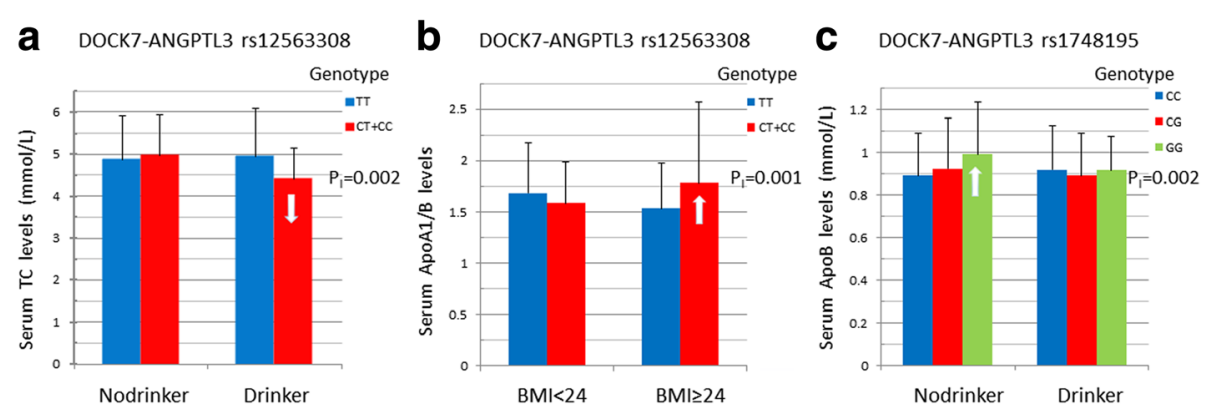

Fig. 1 Interactions of the DOCK7-ANGPTL3 SNPs and sex, age, BMI, smoking and drinking on serum lipid levels in controls. TC, total cholesterol; BMl, body mass index; ApoA1/ApoB, apolipoprotein A1/ apolipoprotein B ratio. The differences in serum TC levels and ApoA1/ApoB ratio among the genotypes were assessed using analysis of covariance. The interactions of the genotypes and alcohol consumption or BMl $\geq 24 \mathrm{~kg} / \mathrm{m}^{2}$ on serum lipid levels were detected by using a factorial regression analysis after controlling for potential confounders $\left(P_{1}\right)$. $\mathbf{a}$, the rs $12563308 \mathrm{CT} / \mathrm{CC}$ genotypes interacted with alcohol to decrease $(\downarrow)$ serum TC levels; b, the rs $12563308 \mathrm{CT} / \mathrm{CC}$ genotypes interacted with BMl $\geq 24 \mathrm{~kg} / \mathrm{m} 2$ to increase $(\uparrow)$ the ApoA1/ApoB ratio; and c, the rs1748195GG genotype interacted with alcohol to decrease $(\downarrow)$ serum ApoB levels 
Table 7 Gene-environment interactions on the risk of CAD and IS

\begin{tabular}{|c|c|c|c|c|}
\hline \multirow[t]{2}{*}{ Factor } & \multicolumn{2}{|c|}{ Rs1748195 } & \multicolumn{2}{|c|}{ Rs12563308 } \\
\hline & $P_{C A D}$ & $P_{\text {IS }}$ & $P_{\text {CAD }}$ & $P_{\text {IS }}$ \\
\hline Sex (male vs. female) & 0.507 & 0.932 & 0.016 & 0.007 \\
\hline Age ( $\leq 60$ vs. $>60$ year) & 0.972 & 0.374 & 0.482 & 0.411 \\
\hline $\mathrm{BMI}\left(\leq 24\right.$ vs. $\left.>24 \mathrm{~kg} / \mathrm{m}^{2}\right)$ & 0.741 & 0.299 & 0.389 & 0.135 \\
\hline Smoking (yes vs. no) & 0.905 & 0.811 & 0.827 & 0.851 \\
\hline Drinking (yes vs. no) & 0.983 & 0.902 & 0.010 & 0.013 \\
\hline Hypertension (yes vs. no) & 0.005 & 0.458 & 0.019 & 0.582 \\
\hline Hyperlipidemia (yes vs. no) & 0.744 & 0.980 & 0.453 & 0.123 \\
\hline
\end{tabular}

$P_{\mathrm{CAD}}$, the $P$ value between CAD patients and controls; $P_{\mathrm{IS}}$, the $P$ value between IS patients and controls; $B M I$ body mass index. The $P$ values for interactions of genotypes and sex, age, BMI, drinking, smoking, hypertension, hyperlipidemia on the risk of CAD/IS were obtained from unconditional logistic regression after all the environmental factors were adjusted, and a $P<0.025$ was considered statistically significant after Bonferroni correction

\section{Haplotype-environment interactions on the risk of CAD and IS}

The interactions of several haplotypes and environment factors on the risk of CAD/IS were also noted in this study. When one of the environmental factors was detected, the rest six factors of sex, age, BMI, smoking, alcohol consumption, hypertension and hyperlipidemia were adjusted.

For the interactions of the haplotypes and hypertension on the risk of CAD/IS, as compared with the same haplotype in normotensive participants, the rs1748195Crs12563308T-hypertension ( $\mathrm{OR}=2.98,95 \% \mathrm{CI}=2.07-4.30)$ and rs1748195G-rs12563308T-hypertension (OR $=2.49$, 95\% CI $=1.66-3.74)$ interactions were associated with an increased risk of CAD. For the normotensive subjects, as compared with the rs1748195C-rs12563308T haplotype, the rs1748195G-rs12563308T haplotype (OR $=1.47$, $95 \% \mathrm{CI}=1.09-1.99)$ was associated with an increased risk of CAD.
For the interactions of the haplotypes and drinking on the risk of CAD/IS, as compared with the same haplotype in non-drinkers, the rs1748195G-rs12563308Tdrinking $(\mathrm{OR}=0.71,95 \% \mathrm{CI}=0.36-0.89)$ and rs1748195Grs $12563308 \mathrm{C}$-drinking $\quad(\mathrm{OR}=0.26,95 \% \quad \mathrm{CI}=0.11-0.58)$ interactions were associated with a decreased risk of CAD. The rs1748195G-rs12563308T-drinking (OR =0.38, 95\% $\mathrm{CI}=0.23-0.61) \quad$ and $\quad$ rs1748195G-rs12563308C-drinking $(\mathrm{OR}=0.24,95 \% \mathrm{CI}=0.10-0.55)$ interactions were also associated with a decreased risk of IS. For the non-drinkers, as compared with the rs1748195C-rs12563308T haplotype, the rs1748195G-rs12563308T haplotype was associated with an increased risk of $C A D(O R=1.38$, $95 \% \mathrm{CI}=1.04-1.84)$.

\section{Discussion}

The results of the present study showed that the genotypic and allelic frequencies of the DOCK7 rs1748195 SNP were different between CAD and controls $(P<0.05$ for each), the $G$ allele frequency was significantly higher in CAD than in controls $(27.6 \%$ vs. $23.6 \%, P=0.024)$. The genotypic frequency of the ANGPTL3 rs12563308 SNP was also different between CAD and controls $(P=0.021)$. The DOCK7 rs1748195 SNP and rs1748195G-rs12563308T haplotype were associated with an increased risk of CAD (Recessive: $\mathrm{OR}=1.79,95 \% \mathrm{CI}=1.04-3.06, \quad P=0.017$, Log-additive: $\mathrm{OR}=1.27,95 \% \mathrm{CI}=1.02-1.57, P=0.014$; $\mathrm{OR}=1.37,95 \% \mathrm{CI}=1.08-1.74, P=0.009$; respectively) and the severity to coronary atherosclerosis $(\mathrm{OR}=1.46$, 95\% CI $=1.05-2.03, P=0.023)$, whereas the ANGPTL3 rs12563308 SNP was associated with a decreased risk of CAD (Dominant: $\mathrm{OR}=0.69,95 \% \mathrm{CI}=0.45-0.94, P=0.011$; Log-additive: $\mathrm{OR}=0.73,95 \% \mathrm{CI}=0.49-0.89, P=0.009$ ). The interactions of rs12563308-drinking on decreased TC levels; rs12563308-BMI $\left(\geq 24 \mathrm{~kg} / \mathrm{m}^{2}\right)$ on increased ApoA1/ApoB ratio; rs1748195-BMI $\left(\leq 24 \mathrm{~kg} / \mathrm{m}^{2}\right)$ on increased the severity to coronary atherosclerosis;
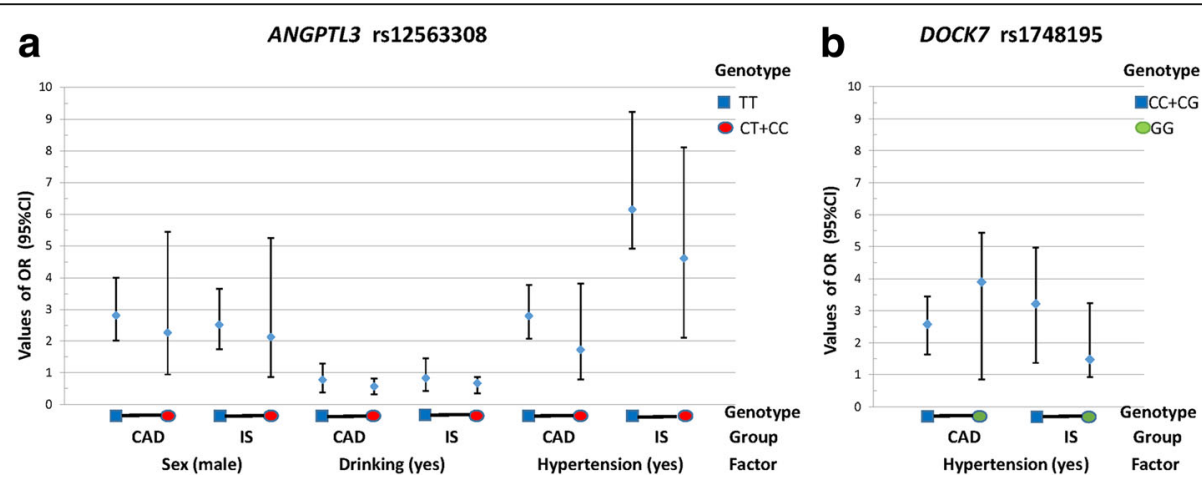

Fig. 2 Gene-environment interactions on the risk of CAD and IS. a the rs12563308 SNP interacted with sex (male), drinking (yes) or hypertension (yes) to influence serum lipid levels in CAD and IS patients; $\mathbf{b}$ the rs1748195 SNP interacted with hypertension (yes) to influence serum lipid levels in CAD and IS patients; CAD, coronary artery disease; IS, ischemic stroke; OR ( $95 \% \mathrm{Cl}$ ), the odds ratio (OR) and $95 \%$ confidence interval ( $95 \% \mathrm{Cl}$ ) 
Table 8 Linkage disequilibrium analysis of the DOCK7-ANGPTL3 SNPS and the association of haplotypes and the risk of atherosclerosis, CAD and IS

\begin{tabular}{|c|c|c|c|c|c|c|c|}
\hline \multirow[t]{2}{*}{ Group } & \multirow[t]{2}{*}{ Haplotype } & \multirow[t]{2}{*}{ Control Fre. } & \multirow[t]{2}{*}{ Case Fre. } & \multirow[t]{2}{*}{ OR $(95 \% \mathrm{Cl})$} & \multirow[t]{2}{*}{$P$} & \multicolumn{2}{|l|}{ LD } \\
\hline & & & & & & $\overline{D^{\prime}}$ & $r^{2}$ \\
\hline \multirow[t]{4}{*}{ CAS } & $C-T$ & 0.7643 & 0.7064 & 1 & & & \\
\hline & $G-T$ & 0.1815 & 0.2486 & $1.46(1.05-2.03)$ & 0.023 & - & - \\
\hline & $\mathrm{G}-\mathrm{C}$ & 0.0541 & 0.0434 & $0.93(0.51-1.69)$ & 0.820 & & \\
\hline & Rare & * & * & & & & \\
\hline \multirow[t]{4}{*}{ CAD } & $C-T$ & 0.7554 & 0.7224 & 1 & & & \\
\hline & $G-T$ & 0.1722 & 0.2300 & $1.37(1.08-1.74)$ & 0.009 & 0.8838 & 0.3833 \\
\hline & $\mathrm{G}-\mathrm{C}$ & 0.0638 & 0.0464 & $0.90(0.59-1.37)$ & 0.630 & & \\
\hline & Rare & * & $*$ & & & & \\
\hline \multirow[t]{4}{*}{ IS } & $C-T$ & 0.7554 & 0.7514 & 1 & & & \\
\hline & $G-T$ & 0.1722 & 0.1902 & $1.12(0.87-1.45)$ & 0.372 & 0.9060 & 0.4263 \\
\hline & $\mathrm{G}-\mathrm{C}$ & 0.0638 & 0.0584 & $0.95(0.62-1.46)$ & 0.811 & & \\
\hline & Rare & * & * & & & & \\
\hline
\end{tabular}

Control Fre. the frequency of haplotypes in controls, Case Fre. the frequency of haplotypes in CAD/IS patients, CAS coronary atherosclerosis. Group CAS, according to angiographic severity in CAD patients, only one-vessel and more than one-vessel in the three major in the three major coronary arteries were defined as control and case respectively; Group CAD/IS, all the patients in our research; the risk of severity to atherosclerosis and CAD/IS was obtained by unconditional logistic regression, and a $P<0.05$ was considered statistically significant after sex, age, BMI, drinking, smoking, hypertension, hyperlipidemia were adjusted; *, the values of the rare haplotypes were not listed

rs12563308TT-hypertension, rs1748195CC/CG-hypertension, rs1748195C-rs12563308T-hypertension and rs1748195G-rs12563308T-hypertension on increased risk of CAD; rs1748195G-rs12563308T-drinking and rs1748195G-rs12563308C-drinking on decreased risk of CAD; rs1748195G-rs12563308T-drinking and rs1748195G-rs12563308C-drinking on decreased risk of IS; rs12563308TT-sex (male) on increased risk of CAD and IS; and rs12563308CT/CC-drinking on decreased risk of CAD and IS were also observed. To our best knowledge, the present study is the first report to explore the effects of the two DOCK7ANGPTL3 SNPs, their haplotypes, SNP- or haplotypeenvironment interactions on coronary atherosclerosis and the risk of CAD and IS.

In the present study, we showed that the genotypic and allelic frequencies of the DOCK7 rs1748195 SNP and the genotypic frequency of the ANGPTL3 rs12563308 SNP were different between CAD and controls. According to the data from international HapMap project, the rs1748195C and rs1748195G allele frequencies were $74.3 \%$ and $25.7 \%$ in CHB (Han Chinese in Beijing, China); $65.4 \%$ and $34.6 \%$ in GBR (British in England and Scotland); $71.2 \%$ and $28.8 \%$ in MSL (Mende in Sierra Leone); and 59.7\% and $40.3 \%$ in GWD (Gambian in western divisions in the Gambia). The frequencies of rs12563308T and rs12563308C alleles were 94.2\% and 5.8\% in CHB; $88.1 \%$ and $11.9 \%$ in GWD; and $84.1 \%$ and $15.9 \%$ in MSL. These results suggest that the prevalence of the DOCK7 rs1748195 and ANGPTL3 rs12563308 SNPs might have a racial/ethnic specificity.
But more and larger samples of molecular epidemiological investigations are necessary to confirm our findings.

Previous GWASes reported that some DOCK7ANGPTL3 polymorphisms were associated with serum TG and TC levels [17, 31]. Shen et al. [20] showed that the rs1748195 SNP was strongly associated with TG and HDL-C in a Chinese pediatric population. In the present study, however, we found that the DOCK7 rs1748195 and ANGPTL3 rs12563308 SNPs were not associated with all of seven serum lipid traits in the controls $(P>0.025$ for all). The reason for these discrepancies in different investigations is still unclear. In addition to different genetic background, sample size, different statistical method, and different gene-gene or geneenvironment interactions may also contribute to the discrepancies among our study and other studies in different populations. Interestingly, in this study in controls, we found that the ANGPTL3 rs12563308 SNP interacted with alcohol consumption to decrease serum TC levels, and interacted with $\mathrm{BMI} \geq 24 \mathrm{~kg} / \mathrm{m}^{2}$ to increase the ApoA1/ApoB ratio. The DOCK7 rs1748195 SNP also interacted with alcohol consumption to decrease serum ApoB levels. These results suggest that the mechanism of the two SNPs to influence lipid metabolism may be different. For the DOCK7 rs1748195 SNP, it not only affected promoter factors to bind motif Hoxa11, but also made effect on post-transcriptional regulation when its base sequence was changed [32]. But this phenomenon was not observed in the ANGPTL3 rs12563308 SNP. We speculated that incomplete linkage-disequilibrium of the 


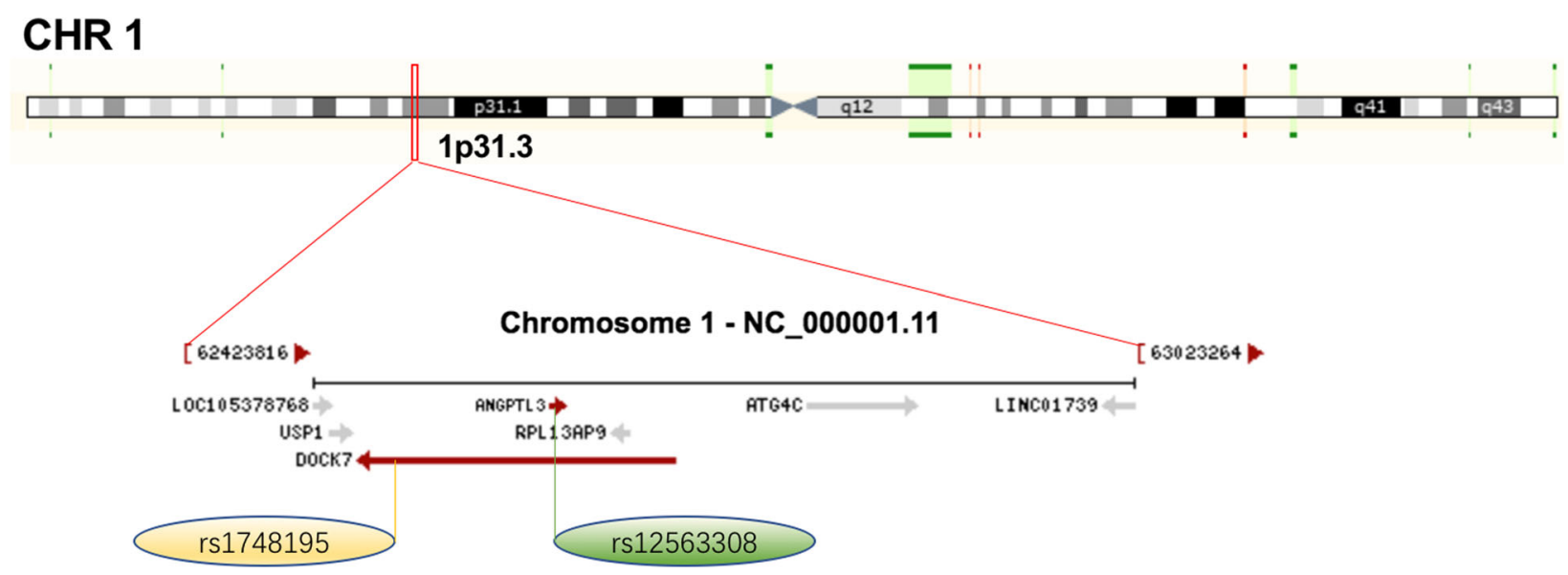

Fig. 3 The positions of the DOCK7 rs1748195 and ANGPTL3 rs12563308 variants

DOCK7 rs1748195 SNP and carried different haplotypes with other SNPs may change genes' functions. Thus, the two DOCK7-ANGPTL3 SNPs may be indirectly involved in lipid metabolism.

The association between the two SNPs and the risk of CHD and IS is not well known. In the current study, we showed that the DOCK7 rs1748195 SNP and rs1748195Grs12563308T haplotype were associated with an increased risk of CAD and the severity to coronary atherosclerosis, whereas the ANGPTL3 rs12563308 SNP was associated with a decreased risk of CAD. The interactions of the two SNPs and several environmental factors on serum lipid levels, the severity to coronary atherosclerosis, and the risk of CAD and IS were also detected. The reasons for these differences may be related to the following factors: 1 ) The DOCK7 rs1748195 SNP is allele $\mathrm{C}>\mathrm{G}$ conversion, whereas the ANGPTL3 rs12563308 SNP is $\mathrm{T}>\mathrm{C}$ conversion. The $\mathrm{G} / \mathrm{T}$ allele carriers had higher risk of CAD than the G/T allele non-carriers (CC genotypes). 2) There may be different linkage-disequilibrium of the two SNPs and/or carry different haplotypes with other SNPs. 3) Although the ANGPTL3 lies within an intron of DOCK7 (Fig. 3), the expression products after mutation may be different. Study has found that TATA-box binding protein associated factor 1 (TAF1) as an enhancer for transcription factor binding with ANGPTL3 to regulate the DOCK7 [33]. Thus, the ANGPTL3 can influence the transcription of the DOCK7 (Fig. 4). 4) In addition, CAD and IS are two different diseases. Although a strong association has been found between CAD and IS, there are also many different aspects between the two diseases. The CAD and IS cases in this study were independent individuals who were exposed to different genetic and environmental risk factors. The results of exposure to different lifestyle and environmental factors probably further modify the association of genetic polymorphisms and the risk of CAD and IS in our study

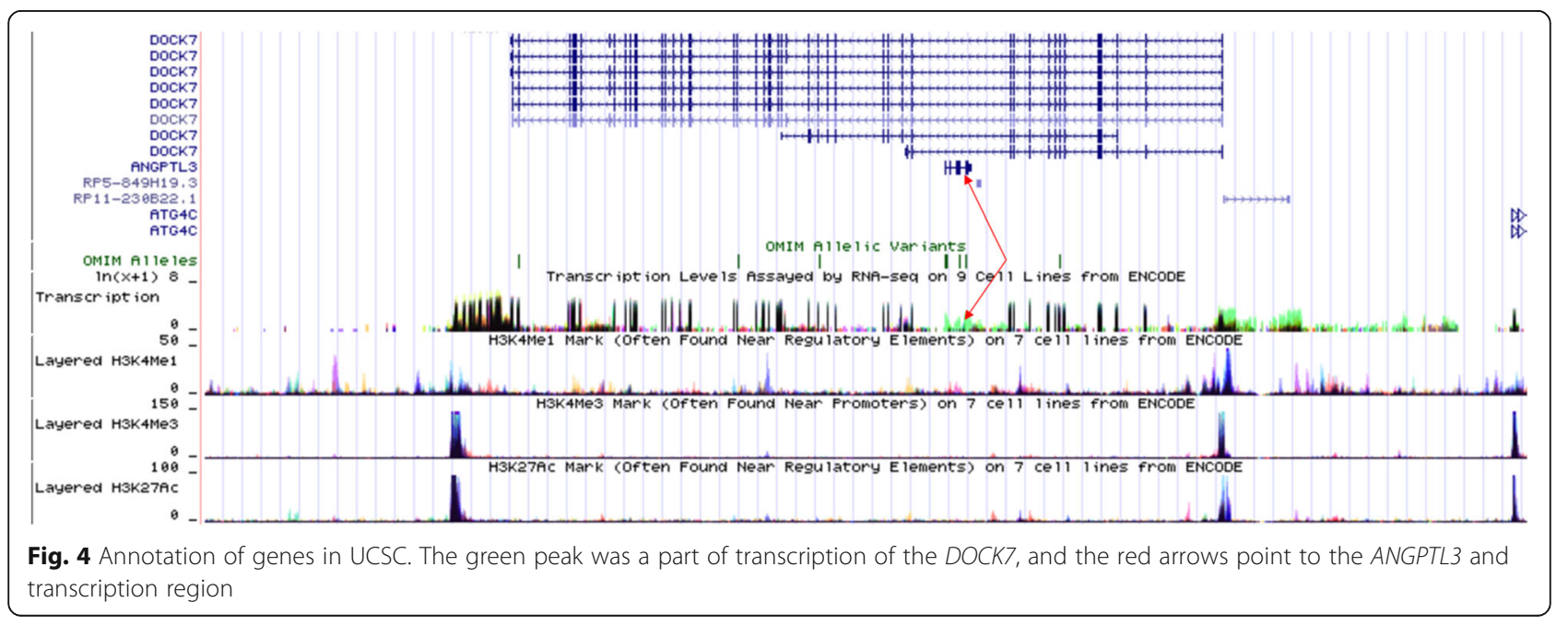


populations. Two recent studies indicated that ANGPTL3 might be a promising therapeutic target in patients with dyslipidemia who are at risk of atherosclerotic cardiovascular disease [18, 34]. Dewey et al. [34] reported that a loss-of-function variant in ANGPTL3 was associated with a $41 \%$ lower risk of $\mathrm{CAD}(\mathrm{OR}=0.59,95 \% \mathrm{CI}=$ 0.14-0.85, $P=0.004$ ). They also found that the human anti-ANGPTL3 monoclonal antibody, evinacumab could cause a reduction in fasting TG levels of up to $76 \%$ and LDL-C levels of up to $23 \%$ in 83 healthy human volunteers. Stitziel et al. [35] also reported that ANGPTL3 deficiency was associated with protection from CAD.

\section{Limitations}

Several potential limitations should be acknowledged in this study. Firstly, the sample size was relatively small compared to many GWASes and replication investigations. Therefore, larger sample sizes are needed to confirm our findings. Secondly, although several confounders have been adjusted for the statistical analyses in this study, several environmental factors such as BMI and blood pressure were different between cases and controls. We could not completely exclude the potential influence of these factors on the results. Thirdly, we could not analyze the association of the DOCK7-ANGPTL3 rs1748195 and rs12563308 SNPs and serum lipid levels in the CAD/ IS patients because of the influence of lipid-lower drugs. Finally, it is well known that both CAD and IS are complex multifactorial disorder. Although we have detected the association of two DOCK7-ANGPTL3 SNPs and their haplotypes with serum lipid levels and the risk of CAD and IS in this study, there are still many unmeasured genetic and environmental factors and their interactions. Thus, our results still need to be confirmed in the other populations with larger sample sizes.

\section{Conclusions}

This study showed that the DOCK7 rs1748195 SNP and rs1748195G-rs12563308T haplotype were associated with an increased risk of CAD and the severity to coronary atherosclerosis, whereas the ANGPTL3 rs12563308 SNP was associated with a decreased risk of CAD. The interactions of the two SNPs and several environmental factors on serum lipid levels, the severity to coronary atherosclerosis, and the risk of CAD and IS were also observed. These results suggest that the detection of these DOCK7-ANGPTL3 SNPs in our study population may be useful for early diagnosis and future individualized treatment of dyslipidemia, CAD and IS.

\section{Abbreviations}

ANCOVA: Analysis of covariance; ANGPTL3: Angiopoietin like 3 gene; Apo: Apolipoprotein; BMI: Body mass index; CAD: Coronary artery disease; CAS: Coronary atherosclerosis; Cl: Confidence interval; DNA: Deoxyribonucleic acid; DOCK7: Dedicator of cytokinesis 7 gene; GWASes: Genome-wide association studies; HDL-C: High-density lipoprotein cholesterol; HWE: HardyWeinberg equilibrium; IS: ISCHEMIC stroke; LD: Linkage disequilibrium; LDL-C: Low-density lipoprotein cholesterol; MAF: Minor allele frequency; nonHDL-C: Non-high density lipoprotein cholesterol; OR: Odds ratio; SNP: Single nucleotide polymorphism; TAF1: TATA-box binding protein associated factor 1; TC: Total cholesterol; TG: Triglyceride; VLDL: Very low density lipoprotein

\section{Acknowledgements}

Not applicable.

\section{Funding}

This study was supported by the Science Foundation of Guangxi Returned Oversea Scholars (No. 0991004) and the National Natural Science Foundation of China (No. 81460169).

\section{Availability of data and materials}

The datasets generated during the present study are not publicly available, because detailed genetic information of each participant were included in these materials.

\section{Authors' contributions}

W-JL participated in the design, performed the statistical analyses, and drafted the manuscript. R-XY conceived the study, participated in the design, and helped to draft and edit the manuscript. X-LC, W-XC, FH and J-ZW collected the data and the samples. All authors read and approved the final manuscript.

\section{Ethics approval and consent to participate}

All procedures of the investigation were carried out following the rules of the Declaration of Helsinki of 1975 (http://www.wma.net/en/30publications/ 10policies/b3/), revised in 2008. The study design was approved by the Ethics Committee of the First Affiliated Hospital, Guangxi Medical University (No. Lunshen 2009-Guike-018; Jan. 7, 2009). Informed consent was obtained from all participants.

\section{Consent for publication}

Not applicable.

\section{Competing interests}

The authors declare that they have no competing interests.

\section{Publisher's note}

Springer Nature remains neutral with regard to jurisdictional claims in published maps and institutional affiliations.

\section{Author details}

${ }^{1}$ Department of Cardiology, Institute of Cardiovascular Diseases, The First Affiliated Hospital, Guangxi Medical University, 22 Shuangyong Road, Nanning 530021, Guangxi, People's Republic of China. ${ }^{2}$ Department of Neurology, The First Affiliated Hospital, Guangxi Medical University, Nanning 530021, Guangxi, People's Republic of China.

Received: 1 January 2018 Accepted: 8 February 2018

Published online: 17 February 2018

\section{References}

1. Bhatnagar $P$, Wickramasinghe $K$, Wilkins $E$, Townsend $N$. Trends in the epidemiology of cardiovascular disease in the UK. Heart. 2016;102:1945-52.

2. Saito I, Yamagishi K, Kokubo Y, Yatsuya H, Iso H, Sawada N, Inoue M, Tsugane S. Association between mortality and incidence rates of coronary heart disease and stroke: the Japan public health center-based prospective (JPHC) study. Int J Cardiol. 2016;222:281-6.

3. Writing Group Members, Mozaffarian D, Benjamin EJ, Go AS, Arnett DK, Blaha MJ, Cushman M, Das SR, de Ferranti S, Després JP, et al. Executive summary: heart disease and stroke Statistics-2016 update a report from the American Heart Association. Circulation. 2016;133:447-54. 
4. Roth GA, Johnson C, Abajobir A, Abd-Allah F, Abera SF, Abyu G, Ahmed M, Aksut B, Alam T, Alam K, et al. Global, regional, and national burden of cardiovascular diseases for 10 causes, 1990 to 2015. J Am Coll Cardiol. 2017;70:1-25.

5. Chhatriwalla AK, Nicholls SJ, Wang TH, Wolski K, Sipahi I, Crowe T, Schoenhagen P, Kapadia S, Tuzcu EM, Nissen SE. Low levels of low-density lipoprotein cholesterol and blood pressure and progression of coronary atherosclerosis. J Am Coll Cardiol. 2009;53:1110-5.

6. Fischer M, Broeckel U, Holmer S, Baessler A, Hengstenberg C, Mayer B, Erdmann J, Klein G, Riegger G, Jacob HJ, et al. Distinct heritable patterns of angiographic coronary artery disease in families with myocardial infarction. Circulation. 2005;111:855-62.

7. Vargas JD, Manichaikul A, Wang XQ, Rich SS, Rotter JI, Post WS, Polak JF, Budoff MJ, Bluemke DA. Detailed analysis of association between common single nucleotide polymorphisms and subclinical atherosclerosis: the multiethnic study of atherosclerosis. Data Brief. 2016;7:229-42.

8. Goldstein LB, Bushnell CD, Adams RJ, Appel LJ, Braun LT, Chaturvedi S, Creager MA, Culebras A, Eckel RH, Hart RG, et al. Guidelines for the primary prevention of stroke: a guideline for healthcare professionals from the American Heart Association/American Stroke Association. Stroke. 2011;42: 517-84.

9. Catapano AL, Reiner Z, De Backer G, Graham I, Taskinen MR, Wiklund O, Agewall S, Alegria E, Chapman M, Durrington $P$, et al. ESC/EAS guidelines for the management of dyslipidaemias the task force for the management of dyslipidaemias of the European Society of Cardiology (ESC) and the European atherosclerosis society (EAS). Atherosclerosis. 2011;217:3-46.

10. Klatsky AL. Alcohol and cardiovascular diseases: where do we stand today? J Intern Med. 2015;278:238-50.

11. Nakanishi R, Berman DS, Budoff MJ, Gransar H, Achenbach S, Al-Mallah M, Andreini D, Cademartiri F, Callister TQ, Chang HJ, et al. Current but not past smoking increases the risk of cardiac events: insights from coronary computed tomographic angiography. Eur Heart J. 2015:36:1031-40.

12. Smith CY, Bailey KR, Emerson JA, Nemetz PN, Roger VL, Palumbo PJ, Edwards WD, Leibson CL. Contributions of increasing obesity and diabetes to slowing decline in subclinical coronary artery disease. J Am Heart Assoc. 2015:4:e001524.

13. Dichgans M, Malik R, König IR, Rosand J, Clarke R, Gretarsdottir S, Thorleifsson G, Mitchell BD, Assimes TL, Levi C, et al. Shared genetic susceptibility to ischemic stroke and coronary artery disease: a genome-wide analysis of common variants. Stroke. 2014;45:24-36

14. Koishi R, Ando Y, Ono M, Shimamura M, Yasumo H, Fujiwara T, Horikoshi H, Furukawa H. ANGPTL3 regulates lipid metabolism in mice. Nat Genet. 2002; 30:151-7.

15. Musunuru K, Pirruccello JP, Do R, Peloso GM, Guiducci C, Sougnez C, Garimella KV, Fisher S, Abreu J, Barry AJ, et al. Exome sequencing, ANGPTL3 mutations, and familial combined hypolipidemia. N Engl J Med. 2010;363: 2220-7

16. Jeemon P, Pettigrew K, Sainsbury C, Prabhakaran D, Padmanabhan S. Implications of discoveries from genome-wide association studies in current cardiovascular practice. World J Cardiol. 2011;3:230-47.

17. Teslovich TM, Musunuru K, Smith AV, Edmondson AC, Stylianou IM, Koseki M, Pirruccello JP, Ripatti S, Chasman DI, Willer CJ, et al. Biological, clinical and population relevance of 95 loci for blood lipids. Nature. 2010;466:707-13.

18. Graham MJ, Lee RG, Brandt TA, Tai LJ, Fu W, Peralta R, Yu R, Hurh E, Paz E, McEvoy BW, et al. Cardiovascular and metabolic effects of ANGPTL3 antisense oligonucleotides. N Engl J Med. 2017;377:222-32.

19. Guo T, Yin RX, Huang F, Yao LM, Lin WX, Pan SL. Association between the DOCK7, PCSK9 and GALNT2 gene polymorphisms and serum lipid levels. Sci Rep. 2016:6:19079.

20. Nie RJ, Yin RX, Huang F, Cao XL, Wu JZ, Chen WX, Li ZM. Two DOCK7 polymorphisms and their haplotypes are associated with the risk of coronary artery disease and ischemic stroke. Int J Clin Exp Pathol. 2016;9:2169-80.

21. Shen $Y$, Xi B, Zhao X, Cheng H, Hou D, Wu L, Wang X, Mi J. Common genetic variants associated with lipid profiles in a Chinese pediatric population. Hum Genet. 2013;132:1275-85.

22. Franceschini N, Carty C, Bůzková P, Reiner AP, Garrett T, Lin Y, Vöckler JS, Hindorff LA, Cole SA, Boerwinkle E, et al. Association of genetic variants and incident coronary heart disease in multiethnic cohorts: the PAGE study. Circ Cardiovasc Genet. 2011;4:661-72
23. Adams HP Jr, Bendixen BH, Kappelle LJ, Biller J, Love BB, Gordon DL, Marsh EE 3rd. Classification of subtype of acute ischemic stroke. Definitions for use in a multicenter clinical trial. TOAST. Trial of org 10172 in acute stroke treatment. Stroke. 1993:24:35-41.

24. Wu DF, Yin RX, Cao XL, Huang F, Wu JZ, Chen WX. MADD-FOLH1 polymorphisms and their haplotypes with serum lipid levels and the risk of coronary heart disease and ischemic stroke in a Chinese Han population. Nutrients. 2016:8:208.

25. Cao XL, Yin RX, Huang F, Wu JZ, Chen WX. Chromosome 9p21 and ABCA1 genetic variants and their interactions on coronary heart disease and ischemic stroke in a Chinese Han population. Int J Mol Sci. 2016;17:586.

26. Chalmers J, MacMahon S, Mancia G, Whitworth J, Beilin L, Hansson L, Neal B, Rodgers A, Ni Mhurchu C, Clark T. 1999 World Health OrganizationInternational Society of Hypertension Guidelines for the management of hypertension. Guidelines sub-committee of the World Health Organization. Clin Exp Hypertens. 1999;21:1009-60.

27. Yin RX, Yang Q, Zhou YJ. Polymorphisms in the FADS1/FADS2 gene cluster are associated with the risk of coronary artery disease and ischemic stroke. J Am Coll Cardiol. 2014;64:C117-8.

28. Yin RX, Zhou YJ, Hong SC. Polymorphisms in the glucokinase regulator gene are associated with serum lipid levels and the risk of coronary artery disease and ischemic stroke. J Am Coll Cardiol. 2014;64:C119.

29. Yang Q, Zhou YJ, Yin RX. Polymorphisms in the MAFB gene are associated with the risk of coronary artery disease and ischemic stroke. J Am Coll Cardiol. 2015;66:C139.

30. Shi Y, He L. SHEsis, a powerful software platform for analyses of linkage disequilibrium, haplotype construction, and genetic association at polymorphism loci. Cell Res. 2005;15:97-8.

31. Aulchenko YS, Ripatti S, Lindqvist I, Boomsma D, Heid IM, Pramstaller PP, Penninx BW, Janssens AC, Wilson JF, Spector T, et al. Loci influencing lipid levels and coronary heart disease risk in 16 European population cohorts. Nat Genet. 2009;41:47-55.

32. Berger MF, Badis G, Gehrke AR, Talukder S, Philippakis AA, Pena-Castillo L, Alleyne TM, Mnaimneh S, Botvinnik OB, Chan ET, et al. Variation in homeodomain DNA binding revealed by high-resolution analysis of sequence preferences. Cell. 2008;133:1266-76.

33. Gertz J, Savic D, Varley KE, Partridge EC, Safi A, Jain P, Cooper GM, Reddy TE, Crawford GE, Myers RM. Distinct properties of cell-type-specific and shared transcription factor binding sites. Mol Cell. 2013;52:25-36.

34. Dewey FE, Gusarova V, Dunbar RL, O'Dushlaine C, Schurmann C, Gottesman O, McCarthy S, Van Hout CV, Bruse S, Dansky HM, et al. Genetic and pharmacologic inactivation of ANGPTL3 and cardiovascular disease. N Engl J Med. 2017;377:211-21.

35. Stitziel NO, Khera AV, Wang $X$, Bierhals AJ, Vourakis AC, Sperry AE, Natarajan $P$, Klarin D, Emdin CA, Zekavat SM, et al. ANGPTL3 deficiency and protection against coronary artery disease. J Am Coll Cardiol. 2017;69:2054-63.

\section{Submit your next manuscript to BioMed Central and we will help you at every step:}

- We accept pre-submission inquiries

- Our selector tool helps you to find the most relevant journal

- We provide round the clock customer support

- Convenient online submission

- Thorough peer review

- Inclusion in PubMed and all major indexing services

- Maximum visibility for your research

Submit your manuscript at www.biomedcentral.com/submit 